\title{
CONTRIBUIÇÕES DOS ESTUDOS CTS PARA A EDUCAÇÃO SUPERIOR NO BRASIL: UMA PERSPECTIVA DE GENERO ${ }_{[1]}$
}

\author{
CONTRIBUCIONES DE LOS ESTUDIOS CTS PARA LA \\ EDUCACIÓN SUPERIOR EN EL BRASIL: UNA \\ PERSPECTIVA DE GÉNERO
}

\section{Resumo}

Joyce Luciane Correia Muzi[2] Nanci Stancki da Luz[3]

Este artigo tem por objetivo entender como os estudos sociais da Ciência e Tecnologia (CTS) possibilitaram discussões em torno da condição das "excluídas" do fazer Ciência e Tecnologia (C\&T), com foco numa instituição de ensino superior - a Universidade Tecnológica Federal do Paraná (UTFPR). Nesse sentido, considerando a universidade como espaço em que se faz C\&T e do qual as mulheres ficaram durante muito tempo excluídas, faz-se necessário recuperar de que maneira elas conseguiram entrar em redutos antes reservados aos homens. Apresentamos uma breve revisão bibliográfica a respeito do campo CTS na América Latina, bem como da perspectiva de feministas a respeito desse campo de estudos. A seguir apresentamos alguns dados levantados durante a pesquisa para a elaboração de minha dissertação para o Programa de Pós-graduação em Tecnologia especialmente sobre a história da UTFPR e sobre a participação das mulheres nesta história. Como resultado, podemos dizer que, graças à interferência do movimento feminista e dos questionamentos em torno dos chamados ideais da Ciência - neutralidade e objetividade - a situação das mulheres em áreas antes inacessíveis foi modificada, permitindo especialmente que elas ingressassem como alunas e como profissionais nas instituições de ensino superior (IES), atuando inclusive na pesquisa científico-tecnológica.

Palavras-chave: CTS, América Latina, educação superior, UTFPR, gênero.

\section{Resumen}

Este artículo tiene por objetivo comprender cómo los estudios sociales de la Ciencia y Tecnología (CTS) permitió discusiones alrededor de la condición de las "excluídas" del hacer Ciencia y Tecnología (C\&T), centrándose en una institución de enseñanza superior - la Universidad Tecnológica Federal del Paraná (UTFPR). En este sentido, considerando la universidad un lugar en que se hace C\&T y del cual las mujeres quedaron durante mucho tiempo excluídas, es necesario recuperar de qué manera ellas lograron entrar en reductos antes reservados a los hombres. Presentamos una breve revisión bibliográfica sobre el campo CTS en la América Latina, así como de la perspectiva de feministas sobre este campo de estudios. A continuación se presentan los datos recogidos durante la investigación para el desarrollo de mi tesis para el Programa de Posgrado en Tecnología en especial en la historia de UTFPR y la participación de las mujeres en esta historia. Como resultado de ello, podemos decir que gracias a la interferencia de los movimientos feministas y de las cuestiones relativas a los llamados ideales de la Ciencia - neutralidad y objetividad - la situación de las mujeres en zonas antes inaccesibles se ha modificado, sobre todo lo que les permite participar como estudiantes y como profesionales en instituciones

№: 21-22 Ano: $13 \quad$ jan/fev/mar/abr/mai/jun 2011 
de educación superior (IES), incluyendo el trabajo en la investigación científica y tecnológica. Palabras-clave: CTS, América Latina, educación superior, UTFPR, género.

\section{Introdução}

Entendemos a Universidade como espaço em que a produção do conhecimento se configura como a ação primeira do fazer científico, logo, essencial. No caso específico da Universidade Tecnológica Federal do Paraná, à formação industrial, tecnológica e profissional, foi unida a perspectiva humanista e, nesse sentido, cabe a nós pesquisadoras e pesquisadores investigarmos a respeito da apropriação dos preceitos da sociologia da Ciência neste meio de produção de conhecimento e assim tentar perceber de que maneira esta mudança proporcionou avanços e ganhos para a sociedade.

A pesquisa que desenvolvemos para a qual o produto final será uma dissertação de mestrado se propõe investigar de que maneira as mulheres participaram do fazer científico em uma instituição que completou em 2009 cem anos de existência. Através de fonte bibliográfica encontrada em vários espaços da instituição, nossa pesquisa considera a história da instituição a partir da perspectiva de gênero - a entrada das meninas nos cursos de formação profissional/industrial e a existência de docentes que participaram do processo de construção da Universidade desde sua criação, pensando no resgate histórico que privilegia a atuação das mulheres enquanto atrizes que muito contribuíram para a consolidação da então Universidade no cenário científico-tecnológico brasileiro. A importância desse resgate está no fato de ser a universidade instituição que se propõe a fazer Ciência e Tecnologia.

\section{O campo CTS}

Os social studies of science emergiram há mais de vinte anos, dos trabalhos de David Bloor, Barry Barnes, Michael Mulkay, como uma prática de análise das Ciências, particularmente britânica. Essa área disciplinar, hoje internacionalizada e institucionalizada, caracteriza-se por uma prática interdisciplinar que tem praticamente levado à invisibilidade as fronteiras entre História, Sociologia, Filosofia das Ciências.

E, ao mesmo tempo que tem atraído a atenção e a ira de antropólogos/as, literatos/as, teóricas feministas, cientistas, muitos dos caminhos recentes da história e da filosofia das Ciências têm sido fundamentalmente moldados pelas possibilidades abertas ou pelos problemas colocados por este tipo de estudo. (LOPES, 1998, p. 354)

Como posto por Lopes (1998), ainda que algumas questões não aparentem servir à causa das feministas, muitas das discussões atuais só são/foram possíveis graças ao 
engendramento dos estudos sociais da Ciência e Tecnologia (C\&T). Os estudos de Ciência, Tecnologia e Sociedade (CTS) "Transformaram radicalmente a noção estabelecida de que a Ciência tivesse qualquer tipo de status epistemológico especial, superior, racional e, portanto, universal" (LOPES, 1998, p. 354), por isso é tão importante tratar do campo e do que ele representa para a situação das mulheres em C\&T. Ele se instituiu devido à necessidade de um campo de estudos que olhasse para as transformações a partir de uma lente social, com o interesse de colocar C\&T no cenário das discussões que não são sociais somente, mas políticas também.

A proposta é a de que se concebesse uma "sociologia da Tecnologia", e, consequentemente, da Ciência, justamente porque havia o reconhecimento de que ela estava em todos os âmbitos de nossa vida, ora sofrendo ora fazendo intervenções (MACKENZIE e WAJCMAN, 1996). Cutcliffe defende CTS como um novo campo acadêmico, por entender que Ciência e Tecnologia são

projetos complexos que se dão em contextos históricos e culturais específicos, nos quais valores culturais, políticos e econômicos nos ajudam a configurar os processos tecnocientíficos, os quais, por sua vez, afetam aos próprios valores e à sociedade que os sustentam (CUTCLIFFE, 2003, p. 18).

Quando o autor fala em "valores culturais, políticos" ele toca em como estas questões sociais/culturais podem transformar os processos que ele vai chamar "tecnocientíficos", e como estes por sua vez vão afetar aqueles valores e a sociedade como um todo. Como a sociedade é o espaço de todos os tipos de relações e interações, pensa-se que estas relações também são afetadas e os agentes destas relações - homens e mulheres - vão "sofrer" os processos e as transformações que deles decorrem.

A opinião de alguns teóricos se complementa; Bazzo et al. (2003) ressalta que os estudos CTS são a "reação acadêmica contra a tradicional concepção essencialista e triunfalista da Ciência e da tecnologia, subjacente aos modelos clássicos de gestão política" (p. 119). Kreimer e Thomas (2004), por sua vez, veem no campo “...la posibilidad de realización de un escenario de democratización política y de desarrollo económico y social" (p. 76), referindo-se especialmente à América Latina, e considerando a interação nos diversos âmbitos da sociedade.

Um ponto importante de toda a discussão pela consolidação do campo CTS é quanto ao "determinismo tecnológico". Marx e Smith (1996) chamam nossa atenção ao fato de que historiadores, publicitários e artistas durante anos auxiliaram no processo de "crença" no "determinismo tecnológico" - eles foram difusores desta crença; palavras como progresso, eficiência, avanço, liberdade aparecem como destaques, sinônimas de C\&T. Em Winner (1996) encontramos a questão de que a inovação tecnológica deveria ser avaliada, prevendo os impactos que ela terá na comunidade e que o que importa "no es la tecnologia misma, sino el sistema social o económico en el que se encarna” (WINNER, 1996, p. 1). Nesse sentido, estes autores caminham para desmistificar a Tecnologia, bem como os processos científicos por trás dela, prevendo que eles não são benéficos por si próprios, ou seja, a intervenção social pressupõe a (in)utilidade dos artefatos ou processos.

Por sua vez Andrew Feenberg (1995) contribui ressaltando a importância de se apresentar o caráter filosófico e político do caminho percorrido pela Ciência e Tecnologia, além de questionar também as instâncias de poder que vão determinar esse caminho. Isso

№: 21-22 Ano: 13 jan/fev/mar/abr/mai/jun 2011 
diz respeito à concepção de C\&T: segundo ele, é necessário que se pense uma democracia, possibilitando a aproximação de outros atores no processo de construção dos artefatos. Os outros atores a que Feenberg se refere ainda não são citados para atender às questões de gênero, embora possamos entender que, quando ele fala em outros, está incluindo nichos da sociedade que não têm a possibilidade de influenciar no processo de concepção/construção dos artefatos, mesmo sendo consideradas de fundamental importância as intervenções dos reais usuários de determinado artefato.

\section{Ciência, tecnologia e sociedade na América Latina}

Uma breve revisão de alguns autores que trataram do campo CTS na América Latina se faz necessário para percebermos que houve a preocupação de alcançar uma autonomia nesta área, já que aqui havia particularidades que exigiam um tratamento diferenciado da Europa ou dos Estados Unidos, correntes mais fortes da área.

Vários autores se preocuparam em evidenciar a importância deste campo de estudos na América Latina, dentre eles Bazzo et al. (2003), com a sua Introdução aos Estudos CTS; Cutcliffe, (2003), com o texto "La emergencia de CTS como campo académico"; e Mackenzie e Wajcman (1996), com o texto "Introductory essay and general issues".

Os textos fazem retrospectivas históricas que nos levam a perceber que não demorou muito a dar-se a devida importância aos estudos CTS no contexto da América Latina, já que estes pensam os antecedentes sociais e as consequências socioambientais voltados às mudanças científico-tecnológicas, estando estas moduladas por fatores sociais, políticos, econômicos, ambientais, éticos e culturais. A proposta é que estes estudos se fixem e permaneçam em todas estas esferas.

Outros autores se preocuparam em registrar a história recente do campo na América Latina, dentre eles Dagnino et al. (1996) com o livro El Pensamiento en Ciencia, Tecnologia y Sociedad en Latinoamérica: uma interpretación política de su trayectoria, no qual descreve os caminhos percorridos pelo PLACTS (Pensamiento Latino Americano en Ciencia, Tecnología y Sociedad), uma não-teoria, que dentre suas propostas está a de ser uma crítica ao "modelo lineal" de desenvolvimento; Kreimer e Thomas (2004) com o livro Un poco de reflexividad o ¿de dónde venimos? Estudios sociales de la ciencia y la tecnología en América Latina; neste livro os autores deixam uma "memória crítica" que chega até o ano em que foi escrito, citando o texto de Dagnino et al. (1996) inclusive como um referencial que vai dar conta da produção CTS em três níveis: contexto, reflexão e política.

Tanto o texto de Kreimer e Thomas como o de Dagnino et al. trazem reflexões sob uma perspectiva sociopolítica, pensando em por meio do estudo das origens do campo (últimos 40 anos do século passado) possibilitar a continuidade evolutiva, ou seja, que haja interesse pela evolução melhorada e constante dos campos de Investigação e Desenvolvimento.

Defende-se que "en PLACTS los análisis se inician a partir del 'escenario social actual"” (DAGNINO et al., 1996, p. 3), o que é exatamente contrário ao pensamento "oficial" daquela época, pelo qual se relegava o social ao segundo plano; mas foi também esta preocupação excessiva por esta "contextualização" que fez com que o "pensamento" chegasse ao "inmovilismo".

Ao chegar às décadas de 1980 e 1990, a realidade acusava as "novas tecnologias" como responsáveis pela "incertidumbre de la economia" (DAGNINO et al., 1996, p. 6) no âmbito da dinâmica tecnológica do período, pela "globalização", que veio suceder a multinacionalização, e o aparecimento das agências reguladoras, no âmbito externo, e crescimento das exportações, "políticas de apertura" e "integración competitiva" (DAGNINO

№: 21-22 Ano: 13 jan/fev/mar/abr/mai/jun 2011 $14 \quad$ Cadernos de Gênero e Tecnologia


et al., 1996, p. 7) no âmbito interno. A reflexão que fazem os autores parte do paralelo das relações apresentadas cronologicamente:

$$
\begin{aligned}
& \text { anos } 60 \text { - sociologia + atividade científica; } \\
& \text { anos } 70 \text { - estudos em CTS; } \\
& \text { anos } 80 \text { - economia + tecnologia. }
\end{aligned}
$$

Os estudos seguem então uma tendência de "diálogo entre enfoques" (DAGNINO et al., 1996, p. 8), não fazendo mais sentido chamar PLACTS às linhas de estudo, pois estas vão "aproveitar" diversas visões de outras disciplinas (como exemplo a problemática ambiental, sociologia do trabalho, teorias econômicas); assim surge a proposta de "Estudios CTS aplicados a Latinoamérica (ECTSAL)", caracterizados fundamentalmente pela diversidade proposta (DAGNINO et al., 1996).

Kreimer e Thomas (2004), nesta mesma lógica, começam criticando a tendência ao debruçamento nas teorias europeias e estadounidenses, já que, por meio destas as comunidades científicas tentavam "resolver" problemas locais; havia portanto, segundo eles, uma necessidade de uma área de estudos sociais de C\&T, como um subgrupo das Ciências Sociais.

Para os autores, ao apresentar as décadas de 60 e 70, importava percorrer os aspectos sociais, cognitivos, institucionais, "generacionales" e espaços sociais de interação, tratando de nos mostrar por que áreas temáticas foi necessário que se passasse para chegar finalmente à formação do campo, enfocando abordagem histórica, perspectivas políticas, sociológicas e antropológicas, e quais aspectos institucionais eram importantes para tal configuração.

As décadas seguintes foram determinantes para a expansão e consolidação do campo CTS. Kreimer e Thomas (2004) dividem o campo em três gerações:

$1^{a}$ - os pioneiros do PLACTS;

$2^{\mathrm{a}}$ - pesquisadores latinoamericanos de formação "extranjera";

$3^{\mathrm{a}}$ - pesquisadores e profissionais que se formaram em cursos criados pela segunda geração.

Os autores vão chamar as décadas de 1960 e 1970 de "fase fundacional del campo", em que surgiam propostas de novos conceitos e explicações “....más derivadas de la experiencia de los autores que de estudios sistemáticos de base empírica...” (KREIMER e THOMAS, 2004, p. 45); já os anos 80 a 2000 serão caracterizados pela ênfase na importância da sociologia e da história da Ciência que prioriza a análise empírica: "estudios de caso, entrevistas, reconstrucción de redes de actores, análisis socioinstitucional, estudios etnometodológicos" (KREIMER e THOMAS, 2004, p. 45).

Tanto Kreimer e Thomas, quanto Dagnino et al., sugerem a importância dessa recuperação histórica como uma forma de consolidação de algo indispensável - uma relação interdisciplinar, com bases sólidas e úteis à sociedade. Por isso Dagnino et al. (1996, p. 12) chegam a manifestar que desejam que os caminhos percorridos até aqui sirvam para "...caracterizar la agenda futura de la reflexión latinoamericana en CTS", deixando de incorrer nos mesmos erros do passado.

Uma perspectiva de gênero

$\mathrm{Na}$ tentantiva de se inserir nestas discussões que envolvem Ciência, Tecnologia e

№: 21-22 Ano: 13 jan/fev/mar/abr/mai/jun 2011 
Sociedade, feministas buscaram bases epistemológicas que justificassem suas causas, em especial aquelas que se voltam a questionar o androcentrismo vigente em toda a Sociedade como também em C\&T.

No século XX, por exemplo, temos os movimentos feministas que se empenharam em recuperar a história das esquecidas ou apagadas da história "oficial" da Ciência e Tecnologia, fato que tenta apagar as marcas deixadas por esses campos que tinham como base a perspectiva de que as mulheres deles não participaram.

François Graña diz que

Los enfoques de género emergentes en la "segunda ola" del feminismo de los años ' 60 a los '80, partían de la denuncia de la escasez de mujeres en las ciencias, para luego detenerse en el carácter androcéntrico del contenido de las ciencias y en los sesgos sexistas del lenguaje. Estos enfoques se orientaban de este modo hacia una revisión profunda de las relaciones entre ciencia y sociedad: "Ya no se trata únicamente de reformar las instituciones y de alfabetizar en ciencia y tecnología a las mujeres, sino de reformar la propia ciencia" (GONZÁLEZ GARCÍA, 1999, apud GRAÑA, 2004, p. 13).

O campo da Ciência, enquanto campo de produção de conhecimento, e o da Tecnologia apresentam a mesma dinâmica. A respeito da Tecnologia especificamente podemos nos basear no que diz François Graña: ela é

una actividad fuertemente masculinizada donde campea al igual que en las "ciencias duras" - la ideología de la "neutralidad" y el conocimiento socialmente aséptico. Las investigaciones señalan una "cultura técnica masculina" como un importante componente identitario, y simétricamente, la incompetencia técnica, la inseguridad y el miedo a la tecnología como parte integrante del estereotipo de género femenino (GRAÑA, 2004, p. 20).

As mulheres não surgem como protagonistas do avanço científico e tecnológico, ao contrário dos homens que seguem estando no centro do que François Graña (2004) vai chamar uma cosmologia que mostra a ciência como "una práctica viril activa y racional dirigida hacia el dominio de la 'madre naturaleza', considerada pasiva, emocional y carnal" (BONDER, 1996, p. 41).

O que nos interessa é que os modelos ou os referentes históricos que estão disponíveis na sociedade são masculinos; estes vão então orientar a atividade científica, de modo que pareça que os homens estiveram e sempre estarão em todas as ordens do saber (GRAÑA, 2004). A Academia portanto como um espaço criado por homens para formação intelectual e construção masculina do conhecimento, representa hoje uma instituição que possibilitou as mudanças que ecoaram na sociedade em geral, isso depois de muita luta e resistência:

La actual situación académica de las mujeres es el resultado complejo de uma incorporación tardía a las instituciones

№: 21-22 Ano: 13 jan/fev/mar/abr/mai/jun 2011 
científicas, un incremento fulgurante de su participación en el último tercio del siglo XX, contribuciones "de alto nivel en algunos casos", una moderada participación en la gestión, y en términos generales, uma discriminación que "...sigue teniendo lugar pero ha adoptado formas más sofisticadas..." (GONZÁLEZ GARCÍA, 1999, apud GRAÑA, 2004, p. 5). Academias.

A autora chama sofisticadas justamente a discriminação que ainda existe dentro das

La discriminación en el ámbito académico asume a menudo la forma de múltiples "micro-desigualdades" que tomadas de una en una parecen insignificantes, pero que contribuyen globalmente a la generación de cierto "clima hostil" que disuade o desmoraliza a las mujeres que han optado por el área científico-tecnológica: “... las mujeres son asignadas a los comités científicos con menos poder, disponen de menos recursos presupuestarios, les es más difícil obtener los servicios del personal de apoyo o se las ubica en oficinas que están lejos; carecen de acceso a las 'redes de iniciados' para obtener información sobre otras instituciones y, a diferencia de los hombres, no disponen de un grupo equivalente de mentores o de modelos a quienes pedir asesoramiento y apoyo" (AGUIRRE e BATTHYÁNY, 2000, apud GRAÑA, 2004, p. 5-6).

Sabemos que ainda que explicitamente não vejamos nada que impeça o acesso das mulheres à Ciência, há um discurso científico que se pretende neutro, mantendo a desigualdade de gênero, impregnando a cultura moderna. A chamada Ciência moderna (positivista, racional, analítica e neutra) preza por suas qualidades nitidamente "masculinas", em oposição à subjetividade, intuição, irracionalidade etc., características atribuídas às mulheres.

A pretensão de "neutralidade" é para Graña "una clave explicativa del éxito fulgurante del discurso científico desde el Renacimiento hasta nuestros días, que lo impone por sobre cualquier otro discurso metafísico, religioso, ético, etc." (SÁNCHEZ GONZÁLEZ, 1999; PUJAL e LLOMBART, 1996, apud GRAÑA, 2004, p. 8). O discurso científico, por sua vez,

siendo androcéntrico, y esta situación perjudica tanto a las mujeres como a los hombres o a la propia ciencia. A las mujeres, porque les obliga a superar una serie de barreras, lo que se empieza a llamar la "barrera de cristal", empleando en ello unas energías y una inteligencia que deberían utilizarse en la creación científica. A los hombres, porque no serán auténticamente libres para vivir y para crear mientras esta libertad no sea compartida con las mujeres. A la ciencia, en fin, porque si rechaza a la mujer, rechaza también un conjunto de valores imprescindibles para la 
creación científica, una parte del patrimonio cultural de la humanidad. El progreso humano y científico se logrará mejor integrando a las mujeres en el eje principal de la cultura dominante (VAN den EYNDE, 1994, apud GRAÑA, 2004, p. 13).

Importante ressaltar que as críticas ao modelo que prevalece de Ciência servem para refletirmos o quão é importante chamarmos atenção para o que se pretendeu ao longo de décadas afirmar: que "el conocimiento en general, y el científico en particular, se caracteriza por su objetividad, por su neutralidad" (SEDEÑO, 2000, s.p.), e que ele se consolida como válido porque o método utilizado está isento de qualquer intervenção subjetiva, distinguindose exatamente pela "búsqueda desinteresada de la verdad mediante la formulación de hipótesis que son contrastadas después mediante técnicas muy elaboradas" (SEDEÑO, 2000, s.p. Grifos da autora.), o que garantiria o valor de seu produto final, livre de erros. Sedeño, relativizando estas questões, crê que, "a no ser que se adopte el 'punto de vista de Dios', es difícil aceptar que lo que sucedió en el pasado, no se volverá a repetir en el futuro y que lo que hoy es 'ciencia buena', conocimiento autorizado o certificado no vaya nunca a dejar de serlo" (SEDEÑO, 2000, s.p. Grifos da autora.).

Pierre Bourdieu também se propôs a problematizar o interesse por trás da concepção de uma "Ciência neutra":

A idéia de uma Ciência neutra é uma ficção, e uma ficção [também] interessada, que permite fazer passar por científico uma forma neutralizada e eufêmica, particularmente eficaz simbolicamente porque particularmente irreconhecível, da representação dominante do mundo social (BOURDIEU, 1983, p. 148)

Esta concepção do autor atende especialmente aos ideais da crítica feminista, que visam desmistificar e derrubar a dominação de um grupo que se identifica como "universal", fazendo "Ciência para todos": nas palavras de Stolte-Heiskanen, 1998, "a Ciência atual é sexista, e esse sexismo acarreta um número de conseqüências epistemológicas, ontológicas, metodológicas e, em última análise, sociais, para o conhecimento produzido" (apud TABAK, 2002, p. 59). As críticas feministas portanto servem de "base para cuestionar una ciencia neutra y libre de valores, así como la naturaleza misma del conocimiento y el poder que éste crea" (SEDEÑO, 2000, s.p.).

Importante dizer ainda que "as pensadoras feministas vêm de há muito colocando em questionamento os parâmetros científicos definidores de quem pode ou não ser sujeito do conhecimento, do que pode consistir como conhecimento, ou mesmo o que pode ser conhecido" (SARDENBERG, 2007, s.p.), e isso só foi possível - questionar a hegemonia da Ciência - após longos anos de luta e empenho dos grupos de mulheres e das feministas, que terão na transformação dessa luta em causa política, que, por sua vez, terá no conceito de gênero[4] o cerne das discussões, algo que foi possibilitado pelos caminhos abertos pelos estudos CTS.

Interessa-nos, finalmente, considerando as críticas feministas ou não, refletir se todos os interessados e interessadas estão fazendo parte dessa construção, passando então basicamente pelas "abordagens de construção social da Ciência e da tecnologia [as quais] argumentam que estas são instituições sociais e não agentes autônomos. A questão principal

№: 21-22 Ano: 13 jan/fev/mar/abr/mai/jun 2011 18 Cadernos de Gênero e Tecnologia 
passa então a ser como a sociedade interfere na construção da Ciência e da tecnologia" (SILVA, 1998, p. 9),

Como uma proposta de política de mudança, Silva (1998) defende que "A construção de um mundo no qual as mulheres não são subordinadas requer: (1) o reconhecimento de que existe subordinação de gênero; (2) o desenvolvimento de uma visão de mundo no qual isso seja possível.” (SILVA, 1998, p. 14).

\section{A educação superior: o caso da Universidade Tecnológica Federal do Paraná}

Em 2009 a Universidade Tecnológica Federal do Paraná completou 100 anos e desde a fundação, como Escola de Aprendizes Artífices (1909), ofereceu ensino profissional/ industrial e, posteriormente, tecnológico/científico aos garotos de camadas menos favorecidas da sociedade, os chamados "desprovidos da sorte". As escolas originalmente apresentavam uma destinação social e humanitária, pois ensinar ofício àquela época garantia que os meninos pudessem sobreviver e sustentar a família.

O tipo de ensino ofertado pela instituição estava intimamente ligado ao tipo de sociedade que se pretendia: ensinar ofício nas áreas de alfaiataria, sapataria, marcenaria e serralheria para os meninos exigia um corpo docente especializado, logo, composto por homens, o que não significava que as mulheres não estavam lá.

Por visar primordialmente à formação profissional a Escola foi elevada ao estatuto de Liceu Industrial do Paraná, em 1937, tendo como grande avanço a instituição do ensino de $1^{\circ}$ grau, atual ensino fundamental.

O ano de 1942 foi determinante para mais uma transformação: a criação da rede federal de instituições de ensino industrial e a Lei Orgânica do Ensino Industrial criaram as Escolas Industriais, por isso o Liceu passou a ser a Escola Técnica de Curitiba. Com a mudança, o ensino passou a ser ministrado em dois ciclos, demandando contratação de novos professores para atuar, no primeiro ciclo de ensino industrial básico, mestria e artesanal, e no segundo, de ensino técnico e pedagógico.

No ano seguinte é dado início aos primeiros cursos técnicos: Construção de Máquinas e Motores, Edificações, Desenho Técnico e Decoração de Interiores, que proporcionará o ingresso de alunas meninas na instituição, majoritariamente e basicamente nos cursos de Edificações e de Decoração de Interiores.

Em 1959 a Instituição foi transformada em Escola Técnica Federal do Paraná, devido à unificação do ensino técnico a nível nacional.

Em 1969, o Governo Federal autorizou as Escolas Técnicas do Paraná e de Minas Gerais a ministrarem Cursos Profissionais de Nível Superior de Curta Duração[5], sendo então criados os Centros de Engenharia de Operação. Os cursos de Engenharia de Operação tiveram tanto destaque que o MEC (Ministério de Educação e Cultura) propôs em 1978 a transformação da Escola Técnica em Centro Federal de Educação Tecnológica do Paraná (CEFET-PR), um fato de extrema importância, já que a partir daí aqueles cursos foram elevados a cursos modelos de Engenharia Industrial. A Lei 6545 de 30/06/78 cria os CEFETs que tinham como objetivos principais o de ministrar aulas nos níveis técnico, tecnológico, formação docente e aperfeiçoamento, e dentre estes o de realizar pesquisas na área técnicoindustrial. A partir desse momento então a Instituição começou a se destacar por sua pesquisa científica, que mais tarde ganhará força com a criação dos Programas de Pós-Graduação, já nos anos 80 .

Na década de 1980 destacamos que se assumiu em relatório trimestral 1984-1987 que até o ano de 1984 inexistia na instituição a "preocupação com a pesquisa a nível

№: 21-22 Ano: 13 jan/fev/mar/abr/mai/jun 2011 
institucional e sistematizada", o que foi corrigido a partir de então com a criação de uma estrutura que permitisse a realização de trabalhos de pesquisa que contassem com o auxílio de professores e professoras que voltavam de programas de pós-graduação do exterior. A pesquisa sofreu percalços em relação à mão-de-obra e espaço físico, no entanto se consolidou rapidamente no campo da pesquisa aplicada, desenvolvida especialmente por três setores: o Núcleo de Pesquisas Tecnológicas, o Núcleo de Engenharia Hospitalar e o Curso de Pósgraduação em Informática Industrial.

O Núcleo de Pesquisas Tecnológicas se propunha a fazer pesquisa a partir de três objetivos: tornar o CEFET-Pr um centro de desenvolvimento de pesquisa aplicada; "desenvolver e adaptar equipamentos didáticos para uso nos laboratórios e oficinas do CEFETPr e de outras instituições de ensino, com vista à melhoria da qualidade de ensino; e desenvolver novas tecnologias para uso da Instituição e de entidades e empresas da comunidade." (Relatório trianual 1984-1987, s.p.). O Núcleo de Engenharia Hospitalar por sua vez tinha como objetivo "Consolidar o Cefet-Pr como um polo regional de referência em Engenharia Biomédica, através de uma atuação eficaz em pesquisa básica, inovação e adaptação tecnológica e prestação de serviços na área de Engenharia Hospitalar, na forma de assessoria técnica e repasse e dissiminação (sic) de conhecimento à comunidade médico hospitalar" (Relatório trianual 1984-1987, s.p.). Como vemos nos objetivos destes dois núcleos é perfeitamente reconhecível o pragmatismo de suas pesquisas.

Numa carta[6] do então diretor Ataíde Moacir Ferrazza ao Governador do Estado do Paraná para solicitar a incorporação de um dado espaço físico para ao CEFET-PR de modo a poder oferecer melhorias no ensino e ampliação do número de vagas nos cursos, o objetivo a respeito da pesquisa desenvolvida no Centro aparece com a seguinte redação: "promover a extensão dos benefícios de suas pesquisas e de sua ação à comunidade mediante cursos e serviços". O olhar portanto, assim como nos primeiros anos da instituição, é de que os produtos por ela gerados deveriam ser revertidos para a sociedade.

Um evento importante aconteceu ainda na década de 1980, mais especificamente em 12 de setembro de 1986: o III Encontro da Mulher[7], que teve por objetivo "identificar e discutir a situação da mulher 'cefetiana', de forma a buscar sua integração". O resultado, segundo os dirigentes, foi eficiente "no sentido de proporcionar segurança no ambiente de trabalho feminino e em todo seu meio social"; uma forma de visibilizar a questão de gênero dentro da instituição que contava com uma média de 30\% de quadro funcional feminino (entre funções de apoio, administrativas, docente e de direção).

Na década de 1990, teremos a expansão do CEFET-Pr para o interior do Paraná, com a implantação de unidades descentralizadas de ensino. Nos anos de 1990 outra transformação marcou essa história: a partir do Decreto n. 2.208 de 17 de abril de 1997 que regulamentava dispositivos da Lei de Diretrizes e Bases da Educação[8] (LDB), a oferta dos cursos técnicos integrados ficou bastante restrita, pois havia previsão de que "A educação profissional de nível técnico terá organização curricular própria e independente do ensino médio, podendo ser oferecida de forma concomitante ou seqüencial a este." (art. $5^{\circ}$. Decreto 2.208/97), legislação que contribuiu para que a instituição implantasse o Ensino Médio e cursos superiores de Tecnologia e extinguisse os cursos técnicos integrados.

Ainda nos anos 90 temos um dado interessante em relação à perspectiva da instituição enquanto uma aspirante à elevação à Universidade: em suas propostas é incorporada a questão humanística como algo imprescindível e esperada de todos os departamentos e núcleos, sejam eles voltados ao Ensino, à Pesquisa ou à Extensão. O discurso no sentido de formalizar e internalizar o slogan "Tecnologia e Humanismo" passa a ser reproduzido nos documentos institucionais oficiais, informativos, projetos, enfim, toda a

\begin{tabular}{llll}
\hline №: 21-22 Ano: $13 \quad$ jan/fev/mar/abr/mai/jun 2011 & $\mathbf{2 0}$ & Cadernos de Gênero e Tecnologia
\end{tabular} 
comunidade se empenha pela proposta de ratificação da instituição como modelo voltado à sociedade.

A esta altura, em relação ao corpo docente da instituição, temos o que Leszczynski caracterizou como "uma escola 'masculina' em suas áreas de excelência" (1996, p. 102). Silva (2000) acrescenta que apesar de um aumento considerável no número de professoras mulheres, a concentração está em áreas de educação geral e em algumas áreas específicas de educação técnica. A exceção colocada pela autora é o que diz respeito ao corpo docente do Departamento de Desenho Industrial (Dadin), originado do Departamento de Decorações, que desde sua origem já tem um número maior de mulheres (SILVA, 2000).

Embora se possa pensar que a mudança de Centro Federal de Educação Tecnológica para Universidade tenha sido fácil, mesmo com toda a história e tradição do então CEFETPr, foi uma longa trajetória que iniciou nos anos 90 e durou sete anos até que o governo federal aprovasse como lei a transformação que ocorreu também devido ao projeto do governo de expansão do ensino superior no país. Em 7 de outubro de 2005 foi criada então a primeira Universidade Tecnológica do Brasil.

$\mathrm{O}$ ano de 2005 também foi bastante importante em relação à formação técnica e tecnológica, pois, após sete anos de extinto o ensino médio integrado à formação de nível técnico, o presidente Lula assinou o Decreto 5.154/2004 que recupera a possibilidade de oferta do ensino integrado - o aluno e a aluna voltam a ter a chance de fazer um só curso e ter um certificado de nível médio-técnico, ou seja, apto a exercer uma profissão.

Tendo se transformado oficialmente em Universidade, a UTFPR teve como grande preocupação dar continuidade a projetos de Ensino, Pesquisa e Extensão, tripé já garantido desde sua transformação em CEFET, nas décadas de 70 e 80.

A transformação então ocorreu a partir da junção de inúmeros esforços, que veem nessa transformação o "atestado" da qualidade e liderança da Escola ao longo da história da educação profissional-tecnológica. Fruto de esforços de várias pessoas, a transformação nada mais é que consequência de anos de dedicação ao ensino técnico e tecnológico; além disso, tínhamos muitos defensores de que a Instituição estaria apta a se tornar Universidade e contribuir para a implementação de uma rede de educação tecnológica, e enquanto tal, integrada, ampliando a pesquisa de maneira a contribuir para a inserção do país no cenário internacional, que enxerga a tecnologia como fator preponderante para a consolidação da pesquisa científico-tecnológica.

Atualmente com 11 campi, distribuídos nas cidades de Apucarana, Campo Mourão, Cornélio Procópio, Dois Vizinhos, Francisco Beltrão, Londrina, Medianeira, Pato Branco, Ponta Grossa, Toledo e capital, a Instituição expande cada dia mais sua oferta de cursos e vagas para discentes, consequentemente, implicando em aumento de vagas para funcionários, dentre eles mais professores e professoras, engajados na e para a continuidade dessa história. Vale destacar que a Instituição tem ampliado os cursos de licenciatura e bacharelados nas áreas de Matemática, Física, Química, Educação Física, Letras, Design, o que pode alterar a configuração de gênero do seu corpo docente. Nos 11 campi há a oferta de cursos de pós-graduação lato e stricto sensu, graduação, em todas as modalidades presenciais - tecnologia, engenharia, licenciatura e bacharelados, nível médio regular com cursos técnicos integrados e um técnico subsequente, além da oferta de nível médio na modalidade de Educação de Jovens e Adultos - Proeja.

Acrescentamos também que nos 11 campi temos 1.393 professores, sendo no total 602 mestres e 340 doutores, 647 técnicos-administrativos e mais de 16.000 alunos matriculados. Os dados abaixo caracterizam especialmente o campus Curitiba em janeiro de 2010:

Gráfico 1: Percentual de docentes segundo sexo no Campus Curitiba

№:21-22 Ano: 13 jan/fev/mar/abr/mai/jun 2011 


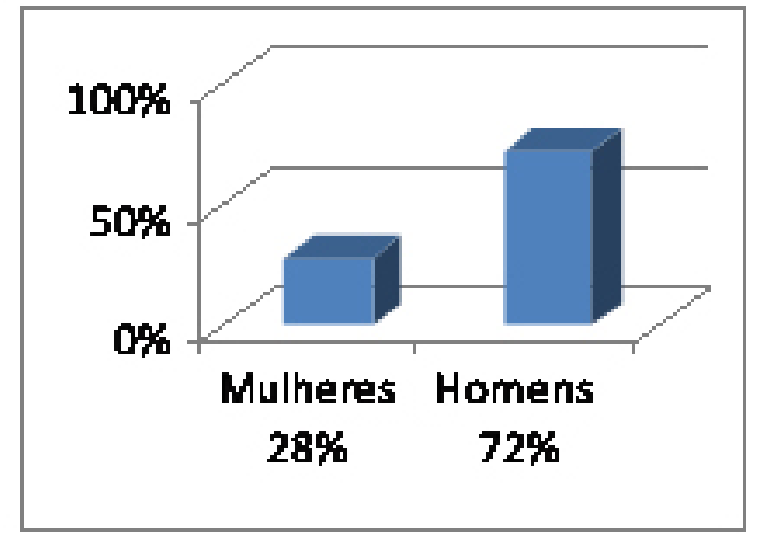

Fonte: www.utfpr.edu.br

Por área do conhecimento, a distribuição fica da seguinte maneira:

\begin{tabular}{lr|l|r}
\multicolumn{2}{c|}{$\begin{array}{c}\text { As mulheres estão } \\
\text { distribuídas: }\end{array}$} & \multicolumn{2}{c}{$\begin{array}{c}\text { Os hounens estão } \\
\text { distnbuídos: }\end{array}$} \\
\hline Humanas & $28 \%$ & Hurnanas & $9 \%$ \\
\hline Saúde/biológicas & $7 \%$ & Saúdelbiológicas & $1 \%$ \\
Ciências "duras" & $65 \%$ & Ciências "duras" & $90 \%$ \\
\hline Total & $100 \%$ & Total & $100 \%$
\end{tabular}

Tabela 1: Percentual de docentes por área do conhecimento no Campus Curitiba Fonte: www.utfpr.edu.br

Percebe-se que por se tratar de um campus em que dos 20 cursos de graduação ofertados atualmente 13 são em áreas de Engenharia e Tecnológicas (65\%), a maioria dos professores são do sexo masculino e estes estão concentrados nas chamadas Ciências "duras", fato difícil de ser modificado considerando a longa tradição mantida pela Instituição.

Ainda assim com uma maioria masculina, podemos afirmar que desde os primeiros anos as mulheres participaram da construção de uma instituição que se tornaria a primeira e única Universidade Tecnológica do país, o que nos leva a confirmar que esta participação foi de extrema importância: no início de funcionamento da Escola elas atuavam diretamente na instrução primária e elementar dos meninos que nela ingressavam. Alguns anos depois, quando da entrada das primeiras alunas, o número de mulheres se mantém pela necessidade de instrução em cursos específicos, como é o caso do de Economia Doméstica e de Corte e Costura. Mais tarde, décadas após a abertura da Escola, quando a instituição se consolida como Centro Federal de Educação Tecnológica, temos ampliadas as áreas de atuação em ensino e pesquisa e vão se fundamentando as bases para a transformação em Universidade. Com isso, a pesquisa científica e tecnológica acaba surgindo como ponto alto de atuação dos e das docentes do

№:21-22 Ano: 13 jan/fev/mar/abr/mai/jun 2011

22

Cadernos de Gênero e Tecnologia 
antigo CEFET-PR.

O que vemos, no entanto, é que ao iniciar suas contribuições na área de pesquisa era baixa ou quase nula a divulgação de pesquisas científicas e tecnológicas feitas por mulheres, seja na condição de líderes ou de colaboradoras.

No Relatório trianual 1984-1987 supracitado não há nomes de participantes dos núcleos e tampouco a designação de líderes das pesquisas elencadas nos relatórios; no entanto, quando se tratava da divulgação em mídia impressa (jornais de circulação regional) das pesquisas feitas no CEFET-Pr, havia a identificação dos pesquisadores e em todos eles encontramos somente homens (fotos 1 a 3). Isso nos leva a questionar se isso se deu por que elas não participavam do fazer científico ou se elas não tinham a mesma visibilidade interna que possibilitasse a divulgação em outros meios.
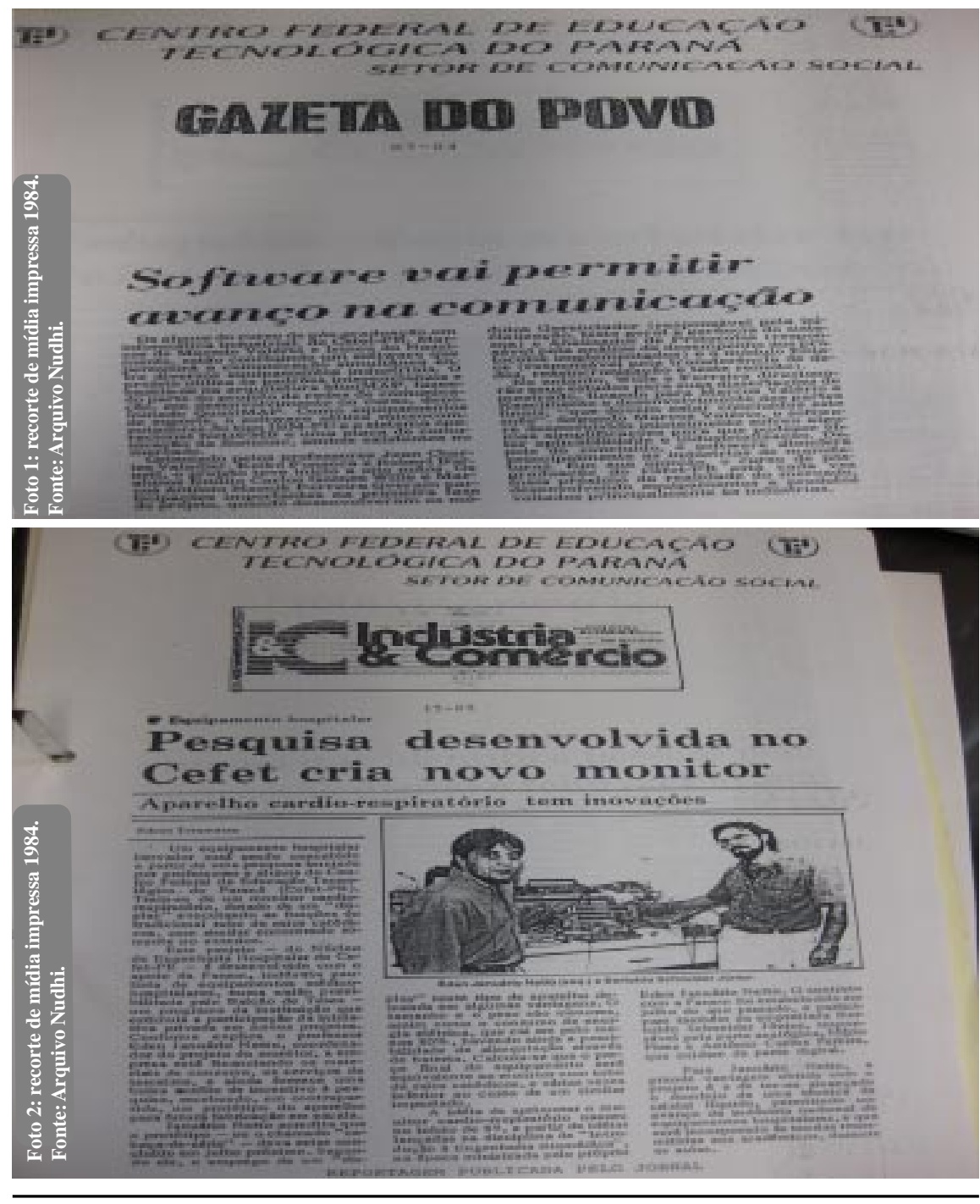

№: 21-22 Ano: 13 jan/fev/mar/abr/mai/jun 2011 


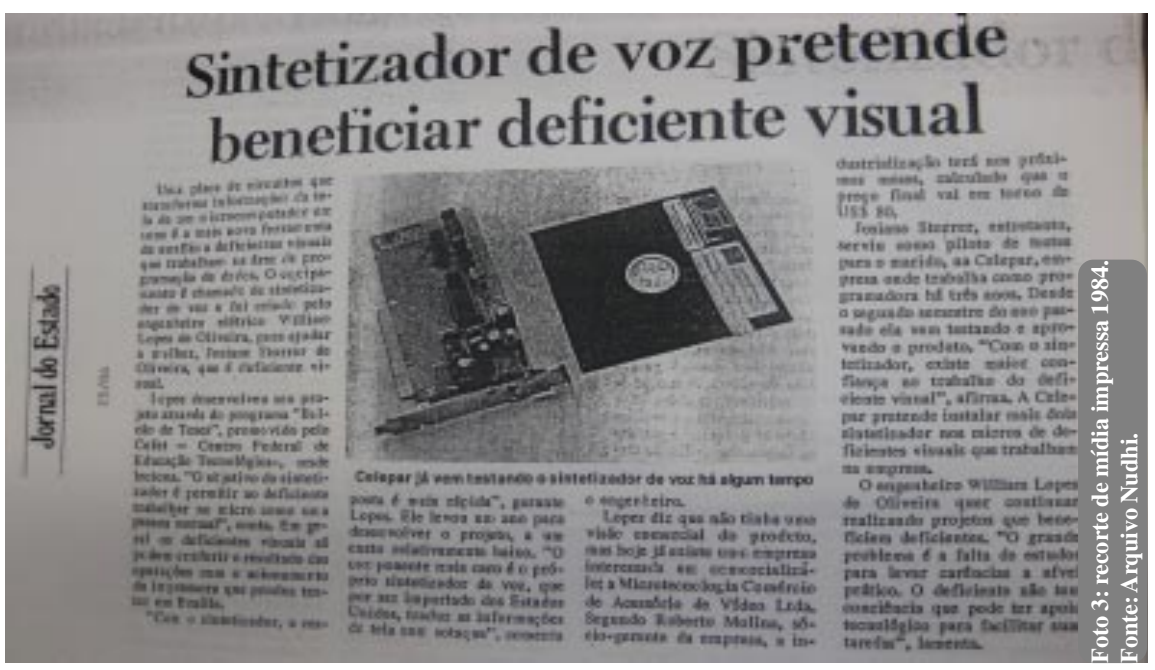

Recentemente, por outro lado, podemos afirmar que isso se dá de forma mais equitativa: em artigo intitulado "Entre cursos e discursos: um olhar sobre mulheres e Ciência na Universidade" [9], constatamos, ao analisar um canal de informação impresso interno da Universidade no qual buscamos verificar se houve no período de um ano divulgação sobre ciência que incluíssem as mulheres, que há divulgação de pesquisas lideradas por homens e mulheres. Com a análise qualitativa de cinco edições do jornal UTFPR Notícias percebemos a preocupação em divulgar sua produção científica, bem como sua concepção de Ciência com vistas a atender ao restante da sociedade; além disso, havia nas edições analisadas, o que nos parece mais importante, considerando o histórico da Instituição e a história da Ciência e da Tecnologia, a preocupação por divulgar o trabalho tanto de homens como das mulheres cientistas, algo que, ao nosso ver, caminha no sentido da equidade esperada, no que tange à visibilização dos atores e atrizes que participam dos processos de construção de C\&T.

\section{Considerações finais}

Ainda que ao olharmos para a história da UTFPR cheguemos à mesma conclusão de inúmeras outras autoras de que a universidade e os próprios campos da Ciência e da Tecnologia tenham se pautado sobre bases androcêntricas e excludentes de pelo menos metade da população, os avanços surgem quando nos debruçamos em análises mais recentes.

No contexto apresentado, vemos que as atuais pesquisas produzidas dentro da UTFPR são divulgadas, sejam elas lideradas ou executadas tanto por homens quanto por mulheres. Não se pode fechar os olhos à trajetória e aos anos de exclusão, porém cabe a nós pensarmos que após os movimentos feministas, ou mesmo dos cientistas interessados pelo fortalecimento do campo CTS, houve inúmeras modificações, a começar pela relativização dos determinismos científico e tecnológico, que propiciaram às mulheres a atuação na Universidade, o avanço em carreiras científicas e tecnológicas, a conquista por novos espaços, enfim.

Atualmente a UTFPR tem 95 grupos de pesquisas cadastrados no Diretório de Grupos de Pesquisa no Brasil na base do CNPq, e 27 são liderados por mulheres, o que representa $28 \%$ do total. Deste total com liderança feminina, a distribuição nas diversas 
áreas de conhecimento é a seguinte:

Tabela 2: Liderança feminina nos grupos de pesquisas da UTFPR cadastrados na base do CNPq

\begin{tabular}{ll}
\hline Área do Conhecimento & Líderes mulheres \\
Ciências Humanas & $41 \%$ \\
Ciências Exatas e da Terra & $22 \%$ \\
Engenharias & $18 \%$ \\
Ciências Agrárias & $11 \%$ \\
Ciências Biológicas & $4 \%$ \\
Ciências Sociais & $4 \%$ \\
Total & $100 \%$ \\
\hline
\end{tabular}

Fonte: Diretório dos Grupos de Pesquisa no Brasil[10].

A tendência apontada por outras pesquisadoras de que as mulheres se concentrem nas Ciências Humanas e menos nas Engenharias aparece nesta tabela; entretanto o número de mulheres nas Engenharias e nas Ciências Exatas e da Terra somados - 40\% - chega quase ao mesmo percentual de mulheres nas Ciências Humanas, o que nos leva a acreditar que um crescente equilíbrio pode estar se configurando.

Diante do exposto, podemos afirmar que não há dúvidas da participação feminina em toda a história da Instituição. Além disso, elas também participam n científica e tecnológica há uma consciência de que as mulheres contribuem significativamente para o avanço, a notar o número de pesquisas lideradas por mulheres divulgadas no ano de 2009 no veículo de comunicação interno. O que se divulga a respeito de Ciência, Tecnologia e mulheres na instituição se configura como uma vitrine na qual podemos ver que todos e todas participam. Isso pode significar que o campo CTS está cada dia mais aberto a outros atores que não aqueles que sempre estiveram à sua frente.

\section{NOTAS}

[1] Este trabalho é parte da dissertação de mestrado da autora deste artigo e foi apresentado nas VIII Jornadas Latinoamericanas de Estudos Sociais da Ciência e Tecnologia em Buenos Aires, de 20 a 23 de Julho de 2010.

[2] Mestre em Tecnologia pela Universidade Tecnológica Federal do Paraná e Mestre em Ciências da Educação pela Universidad del Norte-PY. Professora do Instituto Federal do Paraná. joyce.muzi@ifpr.edu.br

[3] Doutora em Política Científica e Tecnológica pela Universidade Estadual de Campinas (Unicamp). Professora do Programa de Pós-Graduação em Tecnologia (PPGTE) e do Departamento de Matemática (DAMAT) da Universidade Tecnológica Federal do Paranáo (UTFPR). nancist@ terra.com.br

[4] Falar de gênero social atualmente é bem comum, mas a construção do que se entende hoje por gênero é bastante complexa. Adota-se nesse trabalho a concepção de gênero como relacional, constituinte das relações sociais que se estabelecem sobre as diferenças entre sexo feminino e masculino e como uma forma primária de dar significado às relações de poder (SCOTT, 1995, p. 72)

№: 21-22 Ano: 13 jan/fev/mar/abr/mai/jun 2011 
[5] No caso da ETF-PR, foram criados os cursos de Construção Civil e Elétrica, especialmente com o intuito de atender às necessidades regionais do mercado de trabalho da capital.

[6] Na carta não há data, mas imagina-se que ela tenha sido escrita no final da década de 1980 quando o professor Ataíde Moacir Ferrazza estava nos seus primeiros anos como diretor.

[7] Ainda que seja o terceiro encontro, não encontramos vestígios dos anteriores nos documentos analisados.

[8] O Decreto regulamentava o $\S 2^{\circ}$ do art. 36 e os artigos 39 a 42 da Lei n. 9.394, de 20 de dezembro de 1996 (LDB).

[9] Trabalho apresentado no VIII Congresso Iberoamericano em Ciência, Tecnologia e Gênero em 2010, em Curitiba. Entretanto os dados são do ano de 2009.

[10] Disponível em: <http://dgp.cnpq.br/buscaoperacional/> Acesso em: 07 jan. 2010.

\section{Referências}

BAZZO, Walter; LINSINGEN, Irlan Von; TEIXEIRA, Luiz T. V. (2003). Os estudos CTS. In: Introdução aos Estudos CTS (Ciência, Tecnologiae Sociedade). Espanha: OEI.

BONDER, Gloria. El currículum escolar como espejo y ventana de una sociedad equitativa y plural. Buenos Aires: CEM, 1996.

BOURDIEU, Pierre. Sociologia. In: ORTIZ, Renato (Org.). Pierre Bourdieu. São Paulo: Ática, 1983.

CUTCLIFFE, Stephen (2003). La emergência de CTS como campo acadêmico. In: Ideas, Máquinas y Valores. Los estudios de Ciencia, Tecnología y Sociedad. Barcelona: Anthropos.

DAGNINO, Renato; DAVIT, Amilcar; THOMAS, Hernán (1996) El Pensamiento en Ciencia, Tecnologia y Sociedad en Latinoamérica: una interpretación política de su trayectoria. Redes, 7(6), 13-51.

DECRETO No 2.208, DE 17 DE ABRIL DE 1997. Disponível em: <<http://www.planalto.gov.br/ccivil_03/decreto/ D2208.htm > Acesso em: 25 jun. 2010.

FEENBERG, A. Technologyan freedom. In: Alternative Modernity. The Technical Turn in Philosophy and social Theory. Berkeley/Los Angeles: University of California Press, 1995.

GRAÑA, François. Ciencia y tecnología desde una perspectiva de género. Montevidéu: Facultad de Humanidades y Ciencias de la Educación, 2004.

KREIMER, Pablo; THOMAS, Hernán; et al (2004). Un poco de reflexividad o ¿de dónde venimos? Estudios sociales de la ciencia y la tecnología en América Latina. Producción y Uso Social de Conocimientos. Estudios de Sociología de la Ciencia y la Tecnología en América Latina. Bernal, Buenos Aires: Universidad Nacional de Quilmas Editorial.

LESZCZYNSKI, Sonia Ana. Acesso de moças e mulheres a educação técnica e vocacional: um caso brasileiro. Tecnologia e Humanismo, ed. especial, n. 17, Curitiba, 1996.

LOPES, Maria Margaret. “Aventureiras” nas Ciências: refletindo sobre gênero e história das Ciências Naturais no Brasil. Cadernos Pagu, n. 10, 1998, p. 345-368.

MACKENZIE, Donald; WAJCMAN, Judy (1996). Introductory essay and general issues. In: The Social Shaping of Technology. Buckingham, Philadelphia: Open University Press.

Marx, L; Smith, M. R. (Ed.). Does technology drive history? The Dilema of Technological Determinism. Cambridge, Mass: MIT Press, 1996.

ROSEMBERG, Fúlvia; PIZA, Edith P.; MONTENEGRO, Thereza. Mulher e educação formal no Brasil: estado da arte e bibliografia. Brasília: Fundação Carlos Chagas, 1990.

SARDENBERG, Cecilia Maria Bacellar. Da Crítica Feminista à Ciência a uma Ciência Feminista? labrys, études féministes/ estudos feministas, jan./jun. 2007.

SCHIEBINGER, L. O feminismo mudou a ciência? Bauru: Edusc, 2001.

SCOTT, Joan. Gênero: uma categoria útil de análise histórica. Educação e Realidade. Porto Alegre: Faculdade de Educação/ UFRGS, v. 6, n. 2, jul./dez. 1995.

SEDEÑO, Eulalia Pérez. ¿El poder de una ilusión? Ciencia, Género y Feminismo. In: LÓPEZ DE LA VIEJA, M. T. (Ed.). Feminismo: del pasado al presente. 7. ed. Universidad de Salamanca, 2000. Disponível em: <http://www.feminismo.org.br/ portal/index.php?option=com_re

mository $\&$ Itemid=88\&func=fileinfo $\&$ id=125> Acesso em: 25 set. 2009

SILVA, Elizabeth Bortolaia. Des-construindo gênero em Ciência e tecnologia. Cadernos Pagu: gênero, tecnologia e Ciência,

\begin{tabular}{llll}
\hline №: 21-22 Ano: 13 & jan/fev/mar/abr/mai/jun 2011 & $\mathbf{2 6}$ & Cadernos de Gênero e Tecnologia
\end{tabular}


n. 10. Campinas: Núcleo de Estudos de Gênero-Unicamp, 1998, p. 7-20.

SILVA, Nanci Stanki. Gênero e trabalho feminino: estudo sobre as representações de alunos(as) dos cursos técnicos de Deseho Industrial e Mecânica do CEFET-PR. Dissertação (Mestrado em Tecnologia) - Centro Federal de Educação Tecnológica do Paraná. 2000.

TABAK, Fanny. O laboratório de Pandora: estudos sobre a Ciência no feminino. Rio de Janeiro: Garamond, 2002. 
Cadernos de Gênero e Tecnologia 